\title{
Jelte Olthof
}

\section{Verzet in de Friese Wouden}

\section{Het Kollumer Oproer (1797) en Fries federalistisch verzet aan het eind van de achttiende eeuw}

\begin{abstract}
De Bataafse omwenteling in Nederland wordt vaak voorgesteld als een vreedzame episode, maar in dit artikel laat ik zien dat het verzet tegen de eenheidslogica van het revolutionaire Bataafse bewind in de noordoostelijke Friese Wouden in februari 1797 kortstondig een fel en gewelddadig karakter kreeg.
\end{abstract}

Nederland staat niet bekend als een land met een grote revolutionaire traditie. De ironie wil dat juist de meest revolutionaire episode-in de moderne zin des woords-uit de vaderlandse geschiedenis hieraan debet is. Waar de Amerikaanse en Franse republieken jaarlijks trots hun revolutionaire roots vieren op respectievelijk 4 en 14 juli, staan wij, in het land van de Opstand die Franse en Amerikaanse revolutionairen inspireerde, nauwelijks stil bij het feit dat ons land uit verzet is geboren. Een belangrijke verklaring hiervoor is dat die ene politieke revolutie die in 1795 in Nederland plaatsvond uiteindelijk uitmondde in de vorming van het huidige koninkrijk. Hoewel het nota bene Willem van Oranje en diens broers waren die de leiding namen in de Opstand, moet het toch wat ongemakkelijk gevoeld hebben voor hun inmiddels koninklijke nazaten om hun soevereiniteit te legitimeren aan de hand van een opstand tegen een legitieme vorst zoals zijzelf.

In vergelijking met Frankrijk was de Nederlandse Revolutie in veel opzichten een wat tamme bedoeling. ${ }^{1}$ Simon Schama betwijfelt zelfs of we wel van een revolutie kunnen spreken. 'There was now a Batavian Republic', stelt hij over het jaar 1795, 'But had there been a Dutch revolution?'” Anderen, zoals Joost Rosendaal, twijfelen niet aan het revolutionaire karakter van de omwenteling aan het eind van de achttiende eeuw, maar leggen wel de nadruk op het specifiek Nederlandse karakter ervan. ${ }^{3}$ Mijn bedoeling in dit artikel is niet zozeer om dit beeld volledig te ontkrachten, maar wat te nuanceren. In sommige delen van Nederland ging de revolutie wel degelijk gepaard met 
Olthof

onrust, verzet en geweld. In tegenstelling tot Frankrijk ging het hier vaak niet om het verzet van aristocraten of priesters tegen het verlies van particuliere privileges, maar van provinciale bestuurders en burgers tegen van hogerhand opgelegd beleid dat provinciale of lokale privileges en autonomie bedreigden. Het verzet tegen de centralisatieplannen van de Bataafse machthebbers in Den Haag vond plaats van Zeeland tot Groningen, maar in mijn bijdrage wil ik dieper ingaan op de provincie Friesland, waar het verzet een bijzonder fel en bloedig karakter kreeg.

In dit artikel wil ik de spanning tussen de retoriek van nationale eenheid en de praktijk van regionale verscheidenheid in de Bataafse Republiek in het algemeen, en in Friesland in het bijzonder, nader onder de loep nemen. Ik zal laten zien hoe de Franse revolutionaire eenheidslogica (la République une et indivisible) door Fries-Bataafse revolutionairen werd uitgedragen en verdedigd in woord en daad én hoe dit door gematigde revolutionairen en uitgesproken contrarevolutionairen werd ontvangen, betwist en bevochten. In mijn ogen vormt het Friese verzet een bescheiden maar interessant onderdeel van het bredere Europese contrarevolutionaire protest in de Age of Revolutions. Om dit punt te illustreren, zal ik wat dieper ingaan op de casestudy van het Kollumer Oproer van 1797, toen die spanning tot een kookpunt steeg. In de regio Kollum kwam aan het eind van de achttiende eeuw een gewelddadige verzetsbeweging op gang tegen centralisatieplannen van het Bataafse bewind, waarbij uiteindelijk een dozijn doden en vele gewonden vielen.

Het is de moeite waard deze strijd eens nader te bekijken. Nu de noodzaak voor verdere Europese integratie en de Europese Unie zelf steeds meer onder druk staan, is het belangrijk ons er aan te blijven herinneren dat de natiestaten waarin we gewend zijn te denken niet vanzelfsprekend zijn. Het Oproer in Kollum laat zien hoe fel het verzet tegen de nationale eenwording in het verleden was. Een beter begrip van de strijd om de eenheidsstaat in het verleden helpt om de situatie in het heden in perspectief te plaatsen.

\section{Fries verzet in mondiaal perspectief}

De zogenaamde Age of Atlantic Revolutions was een periode van spectaculaire vernieuwing in het politieke denken, spreken en handelen. In Noord-Amerika scheidden een dertiental koloniën zich met geweld af van het Britse Rijk, terwijl in Frankrijk en Nederland eeuwenoude dynastieën werden verdreven en, in het geval van Frankrijk, de koning zelfs werd onthoofd. Elk 
van deze revoluties werd gelegitimeerd uit naam van de universele rechten van het soevereine volk. ${ }^{4}$ De Amerikaanse Declaration of Independence van 1776 roemde de 'inalienable rights' van ieder mens, de Franse Déclaration des droits de l'homme (1789) garandeerde de 'droits naturels, inaliénables et sacrés de l'homme,' en de Bataafse Staatsregeling van 1798 (het notoire Dikke Boek) sprak van 'de natuurlijke regten van de Mensch.' Uit al deze documenten komt het universele mensbeeld van het Verlichtingsdenken duidelijk naar voren. ${ }^{5}$

Niet alleen geloofden veel revolutionairen dat iedereen-ongeacht rang of stand-gelijk was, ze voerden actief beleid om deze eenheid op te leggen. Hierin gingen de Franse revolutionairen het verst. In hun ijver het ancien régime met wortel en tak uit te roeien, moesten provincies plaatsmaken voor 83 min of meer gelijke departementen die vaak vernoemd werden naar rivieren en andere geografische ijkpunten. ${ }^{6}$ Zelfs de taal en tijdsaanduiding waren verdacht. Het plaatselijk patois diende vervangen te worden met de eenheidstaal Frans en de invoering van de nieuwe, op de seizoenen gebaseerde, revolutionaire kalender symboliseerde de nieuwe tijd. Uit al deze pogingen om eenheid op te leggen sprak een rotsvast vertrouwen in de maakbaarheid van de mens-of zoals Thomas Paine het verwoorde: 'we have it in our power to begin the world over again."

Deze drang tot uniformiteit stond echter op gespannen voet met de weerbarstige werkelijkheid. Al snel bleek dat 'het volk' uit wiens naam de revolutie was afgekondigd niet eensgezind was en vaak grote moeite had met de revolutionaire hervormingen. In zowel Frankrijk, Amerika, als Nederland ontaardden de revoluties al snel in een strijd tussen aanhangers van eenheid en verscheidenheid. Voorstanders van radicale hervormingen eisten een uniforme eenheidsstaat, terwijl aanhangers van een gematigdere koers ijverden voor decentralisatie en federalisme om recht te doen aan de diversiteit van de jonge republieken. In met name Europa leidde dit tot fel verzet en vochten unitaristen en federalisten tegen het eind van de achttiende eeuw een verbeten en vaak gewelddadige strijd uit. Ook hier komt het bekendste voorbeeld uit Frankrijk, waar een serie boerenopstanden in Bretagne (Chouannerie) en rond het departement Gironde leidden tot een bloedige burgeroorlog die uiteindelijk hardhandig werd neergeslagen. ${ }^{8}$

Dichter bij huis en op veel beperktere schaal vlamde het verzet ook in Friesland op, wat leidde tot een bescheidener, maar niettemin felle strijd. Schama merkt op: 'Before 1795 was out, it was plain that the Batavian Republic was to be a battlefield on which resolutely opposed versions of the Dutch polity 


\section{Olthof}

would contest its sovereignty. ${ }^{19}$ De strijd tussen de door de Franse revolutie geïnspireerde unitaristen en de meer op Amerika georiënteerde federalisten in de Bataafse Nationale Vergadering is vaak en uitgebreid besproken. ${ }^{10}$ Maar juist buiten Den Haag vlamde het verzet tegen de eenheidsstaat het hoogst op en in dit artikel wil ik daar de aandacht op vestigen.

\section{Vrije Friezen}

Nergens in Nederland was tijdens de Bataafse tijd de spanning tussen eenheid en verscheidenheid beter zichtbaar dan in Friesland. De provincie vormde enerzijds een broedplaats en verzamelpunt voor een aantal van de meest radicale revolutionairen als de voormalige Franeker hoogleraar Johan Valckenaer en journalist Gerrit Paape. Anderzijds vocht Friesland tegelijk hartstochtelijk (en tevergeefs) tegen de vorming van een Nederlandse eenheidsstaat. Aanvankelijk behoorden Friese patriotten als Coert Lambertus Van Beyma in woord en daad tot de meest enthousiaste pleitbezorgers voor radicale bestuurlijke vernieuwing in de Republiek, maar na 1795 zagen zij zich in toenemende mate geconfronteerd met de op Franse leest geschoeide eenheidslogica waarin steeds minder plek was voor lokale verschillen. Maar wat maakt nu dat juist in Friesland het verzet zo opvlamde?

Voor het beantwoorden van die vraag is het van belang eerst te benadrukken dat het verzet tegen eenwording in Nederland zeker niet beperkt was tot Friesland. Dit hangt samen met het sterk federale karakter van de Republiek der Zeven Verenigde Nederlanden, waar de Bataafse revolutionairen korte metten mee wilden maken. Onder de oorspronkelijke Unie van Utrecht van 1579 bevond het bestuur van de Republiek zich in een permanente spagaat tussen de eenheid van de gewesten onderling en het behoud van hun particuliere belangen. ${ }^{11}$ Aan de ene kant voerden de gewesten onder andere een gezamenlijk buitenland beleid, maar bleven zij autonoom binnen hun eigen grenzen en was er bijvoorbeeld geen gemeenschappelijke defensiebudget. ${ }^{12}$ De leden van de Staten-Generaal vertegenwoordigden in de eerste plaats hun provincie en waren aan instructies gebonden. Als gevolg hiervan was elke provincie gelijkwaardig, maar in feite was Holland-waar de meerderheid van de bevolking woonde en dat meer dan de helft van de kosten droeg-onbetwist het invloedrijkst. Besluiten werden vaak gemaakt op basis van unanimiteit en het besturen van de Republiek was daarmee een kwestie van laveren tussen de soms onverenigbare belangen van soevereine gewesten die samenwerkten als één. 
Friesland gold binnen de Republiek volgens historicus Hotso Spanninga al in de zeventiende eeuw als het enfant terrible van het bondgenootschap vanwege haar eigengereidheid en weigering om te buigen voor de wil van Holland. ${ }^{13}$ Spanninga verklaart de Friese houding onder meer door te wijzen op het relatieve 'geografische isolement' waarin Friesland zich bevond ten opzichte van Holland, dat werd gezien als een overzees gebied. Spanninga wijst ook op de relatieve autonomie die Friesland ten opzichte van andere gewesten genoot in de Middeleeuwen en dat 'van alle Nederlandse gewesten (...) Friesland ongetwijfeld de minste ervaring [had] met een landsheerlijk bestuur. ${ }^{14}$ Dit alles vertaalde zich in een zekere argwaan en onbuigzaamheid tegenover het centrale gezag dat ook de Friese houding tegenover de revolutionaire machthebbers in Den Haag zou kenmerken. ${ }^{15}$ De spanningen tussen het machtige Holland en de periferie liepen al tijdens de omwenteling van 1795 hoog op. De radicale revolutionairen-vaak bemiddelde burgers in steden als Amsterdam, maar ook Middelburg, Leeuwarden en Dokkumstreefden een uniformering van Nederland naar Franse model na. Een deel van hen was na de mislukte opstand tegen de Oranjes in 1787 naar Frankrijk gevlucht en was in ballingschap bezield geraakt door ideeën over de ondeelbaarheid van soevereiniteit die in Frankrijk de ronde deden en tot de conclusie gekomen dat het noodzakelijk was Nederland te hervormen tot een echte eenheidsstaat. ${ }^{16}$ De ballingen verklaarden, in navolging van de Franse Jakobijnen, de oorlog aan het federalisme dat in hun ogen gelijk stond aan corruptie en onderdrukking. Niet slechts de Oranjes en hun regentenkliek, maar de autonomie van de provincies zelf, werkte volgens hen vriendjespolitiek in de hand en was dus debet aan het verval van de Republiek der Zeven Verenigde Nederlanden.

De strijd tussen de unitaristen en federalisten over de juiste verdeling van soevereiniteit, schulden en alles wat daarmee samenhing hield de Bataafse politiek tot diep in 1798 in haar greep. Friesland was ook in de Bataafse Republiek bij uitstek de regio waar de spanning tussen eenheid en verscheidenheid hoog opliep. De provincie kenmerkte zich door een sterk historische identiteit, gestoeld op de fameuze historische 'Friese Vrijheid,' die aan het eind van de achttiende eeuw nog springlevend was. ${ }^{17}$ Friese bestuurders lieten zich erop voorstaan dat hun gewest niet gekneveld was door feodalisme en ook in het buitenland roemden revolutionairen als de latere Amerikaanse president Adams en de prominente Franse intellectueel Mirabeau de Friezen die volgens hen een mythische oer-vrijheidszin koesterden die in de rest van Europa verloren zou zijn gegaan. ${ }^{18}$ Zoals 


\section{Olthof}

historicus Jacques Kuiper stelt: 'het federalisme zat de Friezen als het ware in het bloed. ${ }^{19}$

Aanvankelijk spitste het conflict tussen unitaristen en federalisten zich toe op de noodzaak voor een verkiezing van een Nationale Vergadering, waartegen Zeeland en Friesland zich tot het laatst bleven verzetten. ${ }^{20}$ In wat al snel een trend op nationaal niveau zou worden, werd het verzet van de Friese provinciale bestuurders pas gebroken nadat gewapende radicalen in januari van 1796 een coup pleegden waarna de gematigde bestuurders werden afgezet en opgesloten in het Blokhuis in Leeuwarden. De gezuiverde volksvertegenwoordiging stemde kort daarop in met de vorming van de Nationale Vergadering. ${ }^{21}$ De coup laat zien hoe verdeeld de Friese revolutionairen onderling waren en dat het verzet tegen een radicalere koers onder de oppervlakte broeide. In het licht van deze gebeurtenissen is het niet verwonderlijk dat juist in Friesland delen van de bevolking zich openlijk en soms met geweld verzetten tegen de eenheidswens van de radicale Bataafse bestuurders. Het bekendste voorbeeld hiervan is het bloedige Kollumer Oproer van 1797, waarin een aantal dorpen in de Friese Wouden (met name Kollum en de Zwaagwesteinde) zich roerden tegen de centralisatieplannen voor de dienstplicht en plaatselijke milities.

\section{Oproer in Kollum}

Het Kollumer Oproer is zonder twijfel de meest bloedige opstand tegen het Bataafse regime in Nederland, maar heeft nooit een prominente plek gekregen in de literatuur over de Bataafse tijd. In de overzichtswerken over de periode-bijvoorbeeld Rosendaal en Jourdan-komt het Oproer niet voor, wat in sommige gevallen samenhangt met de beperking tot hetgeen op nationaal niveau plaatsvond. Zelfs Schama, die in verhouding veel aandacht besteedt aan de gebeurtenissen buiten Holland, rept niet over het Oproer in de Friese wouden. De meest voor de hand liggende verklaring hiervoor is dat het Oproer slechts enkele dagen in februari van 1797 duurde en dat in de Bataafse tijd wel vaker onlusten uitbraken die met geweld werden neergeslagen. ${ }^{22}$ Bovendien vond het Oproer plaats in wat voor velen indertijd-en zelfs vandaag de dag — gezien werd als een uithoek waarvan sommigen zelfs binnen Friesland nooit hadden gehoord. ${ }^{23}$ Tegelijk waren het Oproer en de nasleep ervan ook buiten Friesland veelvuldig in het nieuws en in omvang en felheid uitzonderlijk, aangezien er bij eerdere onrust vrijwel nooit dodelijke slachtoffers vielen. Hoewel het dus voor de hand ligt dat het 
Oproer tegenwoordig buiten de omgeving van Kollum weinig bekendheid geniet, blijft er voor historici genoeg interessants te zeggen over de roerige februaridagen van 1797.

De academische literatuur over het Oproer is dus gering en beperkt zich met name tot het zelfstandig gepubliceerde Het Kollumer Oproer van 1797 uit 1995 van Berend van der Veen en het hoofdstuk dat Jacques Kuiper in zijn proefschrift Een Revolutie Ontrafeld over de Bataafse tijd in Friesland aan het Oproer wijdt. ${ }^{24}$ Zoals de ondertitel van zijn boek aangeeft, wil Van der Veen vooral de 'klein-menselijke verhalen' achter het Oproer vertellen. ${ }^{25}$ 'Niet de historische gebeurtenissen,' zo stelt hij, 'maar de mènsen [sic] achter die gebeurtenissen, met al hun angsten, hun opschepperij, hun bravoure en een doodenkele keer hun dapperheid, komen voor mij op de allereerste plaats. ${ }^{26}$ Van der Veen put rijkelijk uit het primaire bronnenmateriaal om gebeurtenissen tot leven te wekken en Het Kollumer Oproer is daardoor niet alleen erg leesbaar, maar geeft ook een duidelijke chronologie van de gebeurtenissen. Ook Kuiper gaat in zijn zeer volledige overzichtswerk over de Bataafse omwenteling in Friesland dieper in op het Oproer, maar waar Van der Veen ontkent dat er een prinsgezinde samenzwering schuilging achter de gebeurtenissen, wijst Kuiper slechts op het gebrek aan bewijs hiervoor en dat de autoriteiten alle belang hadden verantwoordelijk buiten zichzelf te plaatsen. ${ }^{27}$

De hardnekkigheid van het beeld van het Oproer als uiting van orangistische sympathieën hangt samen met de retoriek die de Bataafse machthebbers bezigden in hun verslagen, die de voornaamste bron vormen. Aangezien deze rapporten geschreven zijn door en vanuit het perspectief van de autoriteiten, zijn zij duidelijk gekleurd door wat ik het 'Bataafse frame' zou willen noemen: alle oproerkraaiers worden als 'oranjeslaven' weggezet en tegenover de dappere, vrijheidlievende en patriottische burgers geplaatst. De stem van de oproerlingen zelf komt in deze stukken amper voor. Geen van de oproerlingen heeft geschriften achtergelaten-we mogen er vanuit gaan dat het overgrote deel van hen amper kon lezen en schrijven. Het perspectief van de oproerlingen is wel opgetekend in de processtukken tegen de hoofdrolspelers, maar aangezien deze onder druk zijn afgenomen is de betrouwbaarheid ervan gering. Van der Veen wijst er terecht op dat oproerlingen alle belang hadden de verantwoordelijkheid voor het Oproer op anderen af te schuiven en, zou ik willen aanvullen, om de mythe van een orangistische samenzwering te voedden. ${ }^{28}$

In mijn ogen vormde het Oproer geen onderdeel van een orangistische 
Olthof

samenzwering, maar moet het vooral gezien worden als een gelegenheidsverzetsbeweging tegen de uniformiteitslogica van de Bataafse bestuurders. Ondanks zijn beperkte duur en bescheiden omvang, past het Kollumer Oproer in de trend van contrarevolutionair geweld tegen de eenheidslogica van revolutionaire nationale overheden. Ook Kuiper houdt hiermee rekening en schrijft dat de onlusten: 'mogelijk (...) het gewelddadige antwoord [waren] van een zeer traditioneel ingestelde bevolking op een snelle machtsontplooiing van de centrale overheid in de regio.' ${ }^{29}$

De directe aanleiding voor het Oproer bevestigt dit beeld. Het geweld in de Friese Wouden was een reactie op de invoering van de algemene dienstplicht vanuit Den Haag in september 1796. De nieuwe Bataafse Gewapende Burgermacht zou in één klap de bestaande schutterijen en burgerkorpsen in één militaire structuur onderbrengen en tegelijk het gebruik van huurlingen onnodig maken. In het Bataafse denken moesten de vrije, onafhankelijke burgers zelf hun natie verdedigen en plaatsten de buitenlanders die het huurlingenleger opmaakten de nieuwe republiek in een afhankelijke situatie. De dienstplicht verplichtte alle mannen tussen de 18 en 45 jaar om deel uit te maken van de nieuwe Bataafse Burgermacht. Bovendien werd er een verplichte financiële contributie geëist, het wapengeld, om de burgerwacht te bekostigen. ${ }^{30}$ Eind 1796 begon Den Haag ernst te maken met de dienstplicht en in januari van het jaar daarop werd begonnen met het registreren van de dienstplichtigen in Friesland. Dit leidde op verschillende plekken tot onrust. In Wommels, ten zuidwesten van Leeuwarden, trokken bewapende dorpsbewoners uit de omgeving naar het rechtshuis om de registratie een halt toe te roepen en werden beambten met de dood bedreigd. ${ }^{31}$ De vlam sloeg pas echt in de pan in de Friese Wouden in februari van dat jaar.

Dat juist in de noordoostelijke Friese Wouden een fel verzet opkwam heeft alles te maken met de zogenaamde heidedorpen en de bevolking die er leefde. Deze dorpen vormden zich rondom bestaande kernen als Kollum op de arme heide- en dalgrond die na veenontginning overbleef. Ze werden bewoond door arbeiders-vaak voormalige veenarbeiders-die hun schamele opbrengsten uit seizoensarbeid aanvulden met bedelen, handel in zelfgemaakte producten en in sommige gevallen met criminaliteit. In zijn studie naar de heidedorpen laat Spahr van der Hoek zien dat de streek werd gekenmerkt door een 'allesoverheersende armoede' en daarmee gepaard gaande gewelddadigheid, zedeloosheid, drankmisbruik alsook minachting voor gezag en grote onderlinge solidariteit en geslotenheid naar buiten toe. ${ }^{32}$ Heidedorpbewoners leefden vaak onder erbarmelijke omstandigheden 
in plaggenhutten (spitketen genaamd) die soms niet meer waren dan een overdekt gat in de grond. De dorpen groeiden snel in de achttiende eeuw als gevolg van de grote gezinnen-zes kinderen was geen uitzondering-en de aanzuigende werking op eenieder die voor wat voor reden uit de omliggende dorpen was verstoten. ${ }^{33}$

Hoewel de precieze aantallen onduidelijk zijn, speelden de inwoners van deze heidedorpen een prominente rol in het Oproer. Met name uit Kollumerzwaag en het oostelijk gelegen Westeinde van dat dorp, Zwaagwesteinde genoemd of de Westereen in het Fries, was het verzet tegen de dienstplicht groot. Hierbij speelde de reeds genoemde afkeer van gezag van buiten (lokaal, provinciaal, nationaal) een belangrijke rol. Weinig heidedorpbewoners voelden er voor de wapens op te nemen voor een republiek waar zij noch om gevraagd hadden, noch iets van verwachtten. De woede richtte zich ook op het feit dat de autoriteiten zichzelf en hun naasten-studenten, ambtenaren, huisknechten-ontsloegen van de dienstplicht alsook van het betalen van het wapengeld dat geïnd werd om de burgermacht te bekostigen.

Toen de plaatselijke autoriteiten in de loop van januari begonnen met het registreren van de dienstplichtigen, was de sfeer in de districten Kollumerland en Dantumadeel om te snijden. Toen de inwoners van Kollumerzwaag op 18 januari naar Kollum werden geroepen voor registratie, vormde zich een gewapende menigte die met geweld en 'onder de alleryslykste vervloekingen en brutaliseeringen' toegang tot het gerecht probeerde te krijgen. ${ }^{34}$ Toen hen gesommeerd werd zich individueel te melden, weigerden zij één voor één om zich te laten registeren. Dit ging volgens de geïntimideerde plaatselijke ambtenaren hier en daar met 'een stuurs en dreigend gelaat' en het zwaaien van een knuppel, en aan het eind van de dag vertrokken de dienstweigeraars zonder een strobreed in de weg gelegd te zijn weer terug naar huis. In Dantumadeel, waartoe Zwaagwesteinde behoorde, voltrok zich eenzelfde schouwspel. Hier bezette een gewapende menigte het gerecht en dreigde dat: 'hy wie zyn Naam of Ouderdom op geeft [aan de ambtenaren], zal onder onze handen sterven! ${ }^{35}$ Aan dit dreigement werd grif gehoor gegeven; Kuiper heeft berekend dat in Dantumadeel en Kollumerland zeker driekwart, en voor Zwaagwesteinde alle, ingezetenen weigerden zich te laten registreren voor de dienstplicht. ${ }^{36}$

Aan het terughoudende optreden van de autoriteiten kwam een eind in de nacht van 2 op 3 februari, toen de notoire raddraaier Abele Reitzes, die een aantal dagen eerder de registratiecommissie had beschimpt met 


\section{Olthof}

Oranjegezinde leuzen, werd gearresteerd en opgesloten in het gerechtshuis van Kollum in afwachting van zijn overplaatsing naar het Blokhuis in Leeuwarden. Het nieuws van Reitzes arrestatie verspreidde zich op vrijdag 3 februari razendsnel over de Friese Wouden en een woedende menigte trok naar Kollum waar zij Reitzes bewaarders met de dood bedreigde en met geweld diens vrijlating gelastte. Hiermee kwam het Oproer in een stroomversnelling. Van der Veen geeft een gedetailleerd overzicht van de kleurrijke oproerlingen-onder wie de Joodse Zwaagwesteinder Salomon Levy en een mysterieuze veteraan die zich voor de Hertog van Brunswijk zelf uitgaf-maar mijn beschrijving van het Oproer beperk ik hier, gezien de ruimte, tot de hoofdzaken.

Nog voor het eind van de dag bereikte het nieuws van de gewelddadige ontzetting van Reitzes in Kollum zowel de autoriteiten in Leeuwarden als Dokkum. Vanuit beide steden vertrok in het holst van de nacht een expeditie van schutters naar Kollum om orde op zaken te stellen. In de dagen daarop voltrok zich een kat en muisspel tussen de opstandelingen en de verschillende schutterskorpsen die zich kriskras door Kollumerland verplaatsten, dan weer elkaar opjagend, dan weer voor elkaar op de vlucht. ${ }^{37}$ Op vrijdag 3 februari wisselden beide kampen voor het eerst schoten uit-de opstandelingen hadden hun vuurwapens buitgemaakt op lokale schutterijen-en vielen de eerste gewonden. Jan Binnes, één van de aanvoerders van het Oproer uit het nabijgelegen Oudwoude, werd overmeesterd en in de Kerk van Kollum vastgezet. Kapitein Hector Feugen, aanvoerder van de Dokkumer schutters, had de rebellen inmiddels nabij Kollumerverlaat verjaagd door hen onder vuur te nemen met zijn veldgeschut. De rebellen hergroepeerden zich echter de volgende dag en joegen Feugen en zijn manschappen op de vlucht terug naar Dokkum. Kollum was nu weer in handen van de oproerlingen, die op gewelddadige wijze wraak namen op de achtergebleven beambten en hun in de kerk opgesloten medestanders prompt bevrijdden. Ook in Dantumadeel brak nu het Oproer los en vernielden gewapende bendes de woningen van plaatselijke notabelen en bedreigden en mishandelden de eigenaren. Hier viel ook het eerste dodelijke slachtoffer van het Oproer: één opstandeling werd neergeschoten nadat hij probeerde een overheidsbeambte te verdrinken. ${ }^{38}$ Heel de noordoostelijke Friese Wouden waren nu in rep en roer en de autoriteiten slaagden er niet in de orde te herstellen.Het Dokkumer korps onder leiding van Feugen trok zich terug achter de muren van hun thuisstad, waarmee ze het veld min of meer aan de opstandelingen liet. De opstandelingen, dronken van zowel de buitgemaakte drank als hun succes, 
trokken daarop naar Dokkum. Hier nam het Oproer een wending. Toen de oproerlingen na het vallen van de avond Dokkum bereikten, toegang tot de stad eisten en weigerden te vertrekken, openden de kanonnen op de stadswal het vuur op hen. Een bloedbad volgde. De rebellen sloegen op de vlucht, vijf doden en talloze zwaargewonden achterlatend. De volgende dag opende het Leeuwarder schutterskorps onder bevel van kolonel Pier van Sloten het vuur op opstandelingen in Kollumerverlaat, waarbij eveneens vijf dodelijke slachtoffers vielen. Op bloedige wijze werd het Oproer gebroken en in de dagen daarna pacificeerden de toegesnelde korpsen de wijde omgeving. De laatste soldaten zouden pas op 23 februari terugkeren naar Leeuwarden, waar hen een waar heldenonthaal te wachten stond.

De nasleep van het Oproer was minstens zo bloedig. De Friese autoriteiten traden hard op tegen degenen die zij verantwoordelijk hielden voor de onlusten. Twee van hen-Jan Binnes en Salomon Levy-werden publiekelijk geëxecuteerd in Leeuwarden. Voor minder prominente oproerlingen volgde een combinatie van soms levenslange verbanning, brandmerken, geseling op het schavot, gevangenisstraf tot tien jaar en veroordeling tot het tuchthuis. ${ }^{39}$ Zelfs voor die tijd waren dit zware straffen en de meedogenloosheid van het Friese revolutionaire bewind schokte zelfs de Franse gezant François Noël. ${ }^{40}$ Hoewel het aantal slachtoffers verbleekt bij de honderdduizenden die omkwamen in de Franse contrarevolutie, was zowel het Oproer als de reactie van de Friese autoriteiten naar Nederlandse begrippen uiterst gewelddadig. ${ }^{41}$ Ook in Den Haag deed het de wenkbrauwen fronsen en werd gediscussieerd of en hoe het radicale bewind in Leeuwarden tot de orde moest worden geroepen. De directe betekenis van het Oproer was dat de bestuurders in Friesland onder het vergrootglas kwamen te liggen, hetgeen wellicht verklaart waarom er na 1797 geen verzet van soortgelijke omvang in de provincie meer plaatsvond. Toen na een staatsgreep in Den Haag ook op nationaal niveau de radicalen aan de macht kwamen, grepen gematigde revolutionairen met Franse hulp in. Achteraf kan dit gezien worden als de opmaat tot de volledige Franse inlijving door Napoléon en afschaffing van de Bataafse republiek in de jaren daarop.

Het Kollumer Oproer laat zien dat de eenwording van Nederland na de Bataafse omwenteling op lokaal niveau verzet opriep dat gepaard ging met intimidatie, vernieling en geweld. Het is van belang te benadrukken dat zowel het verzet zelf als de gewelddadige respons van de autoriteiten een sterk Fries karakter had. Friese bestuurders verzetten zich aan het eind 


\section{Olthof}

van de achttiende eeuw niet alleen tegen centralisering vanuit Den Haag, maar waren onderling ook sterk verdeeld in voor- en tegenstanders van uniformering. Een assertieve en radicale groep revolutionairen trachtte vanuit hun machtscentra in steden als Leeuwarden en Dokkum hun wil op te leggen aan het platteland waar vaak een veel gematigdere koers werd voorgestaan. Dat het juist in de noordoostelijke Friese Wouden tot een opstand kwam, ligt vooral in de antiautoritaire volksaard van de heidedorpbewoners, die de plannen voor centrale Bataafse Burgermacht met achterdocht bezagen. Dit verklaart zowel de felheid als de kortstondigheid van het Oproer, alsook het feit dat het tegenwoordig zelfs in de regio Kollum nog maar weinig bekendheid geniet.

\section{Noten}

1. Jacques Godechot, La Grande Nation: L'Expansion Révolutionnaire de La France Dans Le Monde de 1789 à 1799, 2nd ed. (Paris: Aubier Montaigne, 1983), 185.

2. Simon Schama, Patriots \& Liberators: Revolution in the Netherlands 1780-1813, 2nd ed. (London: Harper, 2005), 211.

3. Joost Rosendaal, De Nederlandse Revolutie: Vrijheid, volk en vaderland 1783-1799 (Nijmegen: Vantilt, 2005).

4. Zie voor Frankrijk: François Furet, Penser La Révolution Française (Paris: Gallimard, 1978); Voor de Nederlandse casus zie het interessante artikel: Peter Van den Berg, "Een Europese Grondwet Zoekt Een 'volk:' Over Het Concept 'Volk van Nederland' Tijdens de Bataafse Revolutie (1795-1798) En de Lessen Voor de Discussie over de Europese Grondwet," in Europa: eenheid in verscheidenheid? Groningse beschouwingen over de Europese Grondwet, eds. F. Amtenbrink en S. B. Van Baalen (Den Haag: Boom, 2005), 1-31.

5. Hierbij moet worden aangetekend dat de meeste revolutionairen het niet zo nauw namen met deze universele principes als het niet-westerse volkeren betrof, zoals de bloedige pogingen van de Franse staat om de zusterrevolutie in de kolonie St. Domingue (het huidige Haïti) te onderdrukken laten zien.

6. Overigens speelde het gewest Holland na 1795 ook met het plan de provincie naar Frans voorbeeld in 50 gelijke districten in te delen, zie: Schama, Patriots \& Liberators: Revolution in the Netherlands 1780-1813, 218.

7. Thomas Paine, Common Sense (Philadelphia: W. and T. Bradford, 1776), 87.

8. Gabriel Du Pontavice, La Chouannerie (Paris: Presses Universitaires de France, 2015); Paul R. Hanson, The Jacobin Republic Under Fire: The Federalist Revolt in the French Revolution (University Park, PA: Pennsylvania State University Press, 2003).

9. Schama, Patriots \& Liberators: Revolution in the Netherlands 1780-1813, 215.

10. Annie Jourdan, La Révoltuion Batave: Entre La France et l'Amérique 1795-1806 
(Rennes: Presses Universitaires de Rennes, 2008), 155-163; en Mart Rutjes, Door Gelijkheid Gegrepen: Democratie, Burgerschap En Staat in Nederland 1795-1801 (Nijmegen: Vantilt, 2012), 42-52.

11. A. Th. Van Deursen, "Tussen eenheid en zelfstandigheid. De toepassing van de Unie als fundamentele wet," in De Unie van Utrecht. Wording en werking van een verbond en een verbondsacte, eds. S. Groenveld en H. L. Ph. Leeuwenberg (Den Haag: Martinus Nijhoff, 1979), 138.

12. Voor de tekst van de Unie zie: S. Groenveld and H. L. Ph. Leeuwenberg, eds., De Unie van Utrecht. Wording En Werking van Een Verbond En Een Verbondsacte (Den Haag: Martinus Nijhoff, 1979), 29-40;

13. Hotze Spanninga, Gulden Vrijheid? Politieke cultuur en staatsvorming in Friesland, 1600-1640 (Hilversum: Verloren, 2012), 37.

14. Ibid., 38-39, 41.

15. Zie: Jelte Olthof, "Fries en Vrij in Revolutietijd," It Beaken 81, no. 1/2 (2019): 2126. Bovenstaande twee alinea's zijn grotendeels aan pagina 18-19 uit dit artikel overgenomen.

16. Jourdan, La Révoltuion Batave: Entre La France et l’Amérique 1795-1806, 149.

17. Olthof, "Fries En Vrij in Revolutietijd," 17; Zie over de oorsprong van deze "Friese Vrijheid:" Oebele Vries, "Frisonica Libertas: Frisian Freedom as an Instance of Medieval Liberty," Journal of Medieval History 41, no. 2 (2015): 229-248.

18. Olthof, "Fries en Vrij in Revolutietijd," 16-17.

19. Jacques Kuiper, Een revolutie ontrafeld: Politiek in Friesland 1795-1798 (Franeker: Van Wijnen, 2002), 20.

20. Kuiper wijst erop dat achter de tegenstelling unitaristen en federalisten in Friesland een gevecht tussen radicale en gematigde revolutionairen schuilging. De radicalen, zo stelt hij, grepen de eenheidslogica vaak aan als "tactisch wapen" om bondgenoten buiten Friesland te vinden voor hun wens om de in hun ogen gesloten bestuurscultuur in Friesland omver te werpen, zie: Een revolutie ontrafeld: Politiek in Friesland 17951798 (Franeker: Van Wijnen, 2002), 99.

21. Ibid., 124-125.

22. Zie voor de rijke geschiedenis van oproeren in de Nederlandse Republiek: Rudolf Dekker, Holland in beroering: oproeren in de 17e en 18e Eeuw (Baarn: Ambo, 1982).

23. Dit laatste blijkt duidelijk uit de verscheidenheid waarmee de betrokken bestuurders en militairen de lokale plaatsnamen aanduiden en spellen.

24. Berend K. van der Veen, Het Kollumer Oproer van 1797: naar de verhalen van de medespelers (Zutphen: Skipper Publishing, 1995); Kuiper, Een Revolutie Ontrafeld zie hoofdstuk 6 "Het Kollumer Oproer van 1797," bladzijdes 256-298.

25. Van der Veen, Het Kollumer Oproer van 1797, 1.

26. Ibid., 2.

27. Ibid., 6; Kuiper, Een revolutie ontrafeld, 268, 291.

28. Van der Veen, Het Kollumer oproer van 1797, 2.

29. Kuiper, Een revolutie ontrafeld, 267.

30. Van der Veen, Het Kollumer oproer van 1797, 6-7.

31. Kuiper, Een revolutie ontrafeld, 262-263. 


\section{Olthof}

32. J. J. Spahr van der Hoek, De Heidedorpen in de Noordelijke Wouden: HistorischSociologische Studie (Drachten: Laverman N.V., 1960), 49.

33. Kuiper, Een revolutie ontrafeld, 266.

34. Aldus het verslag van A. J. C. de Bere, commissielid van de Bataafse Gewapende Burgermacht, in een verslag in de Friesche Courant van 18 februari 1797. Geraadpleegd op www.delpher.nl op 14 januari 2020.

35. Verslag van De Bere, Friesche Courant 18 februari 1797.

36. Kuiper, Een revolutie ontrafeld, 265-266.

37. Het meest uitgebreide verslag van dit kat en muisspel kan gevonden worden in: Van der Veen, Het Kollumer oproer van 1797.

38. Kuiper, Een revolutie ontrafeld, 271.

39. Ibid., 285.

40. Zie diens brief aan ambassadeur Delacroix van 11 ventôse an V (1 maart 1797), waarin hij de executie van Jan Binnes een 'circonstance qui a fait frissonner d'horreur toutes les ames honnêtes' noemt. H. T. Colenbrander, ed., Gedenkstukken Der Algemene Geschiedenis van Nederland van 1795 Tot 1840, vol. 2 ('s Gravenhage: Martinus Nijhoff, 1906), 94.

41. De enige parallel in deze tijd is het fusilleren van een Gelderse edelvrouw die orangistische opstand in haar provincie probeerde te ontketenen, zie: Rosendaal, De Nederlandse Revolutie: Vrijheid, volk en vaderland 1783-1799, 112. 